Rural Sociology 78(1), 2013, pp. 75-108

DOI: $10.1111 /$ ruso. 12000

Copyright (C) 2013, by the Rural Sociological Society

\title{
Farming Systems and Rural Out-Migration in Nang Rong, Thailand, and Chitwan Valley, Nepal*
}

\author{
Martin Piotrowski \\ Department of Sociology \\ University of Oklahoma \\ Dirgha Ghimire \\ Population Studies Center \\ University of Michigan \\ Ronald Rindfuss \\ Department of Sociology \\ University of North Carolina \\ and East West Center
}

\begin{abstract}
Using data from two postfrontier rural settings, Nang Rong, Thailand $(N=2,538)$, and Chitwan Valley, Nepal $(N=876)$, this article examines agricultural push factors determining the out-migration of young people age 15 to 19 . We focus on different dimensions of migration, including distance and duration. Our study examines a wide array of agricultural determinants, each with its own potential effect on migration. These determinants include land tenure, crop portfolios, animal husbandry activities, and use of farm inputs. We link these proximal causes to two underlying mechanisms: risk and amenities. We examine these determinants using separate models across settings. Our results indicate that agricultural factors are significant determinants of migration in both contexts. However, different factors operate in different settings, indicating the importance of contextual variation in explaining the manner in which risks and amenities influence agricultural determinants of migration.
\end{abstract}

\section{Introduction}

Migration from agriculture represents one of the most fundamental shifts in population distribution throughout the world and has profound implications for rural and urban areas both within and across national borders. In advanced industrialized countries historically and in developing countries today, people have relocated en masse, moving from

* Data analysis reported in this article was partially supported by funding from the National Science Foundation (NSF) Partnerships in International Research and Education (PIRE) Early-Career Summer Fellowship. We acknowledge our debt to the large number of people who participated in the collection of the Nang Rong Project and Chitwan Valley Family Study. We also thank three anonymous reviewers for their helpful comments. Direct all correspondence to Martin Piotrowski, of Sociology, University of Oklahoma, 780 Van Vleet Oval, Kaufman Hall 331, Norman, OK 73019, (405) 325-1751; e-mail: piotrow@ ou.edu. 
rural areas to cities in search of work (Brockerhoff 2000; Hathaway 1960). While contemporary migration research puts considerable effort into studying pull factors leading to such migration, as well as intervening obstacles (Curran 2002), push factors, especially agricultural ones, remain understudied, with especially little research on variation across contexts.

Going beyond much of the literature that focuses largely on case studies of single settings using a limited set of agricultural measures, we focus in this article on household-level agricultural push factors as determinants of rural out-migration in two postfrontier agricultural regions-Nang Rong, Thailand, and Chitwan Valley, Nepal. We use detailed data on key aspects of farming systems such as crop portfolios, landholding size, use of farming inputs, and aspects of land tenure that are not available in many leading migration data sets, such as the Mexican Migration Project and the Latin American Migration Project. Our results point to the importance of household-level farming assets and strategies in both settings, as well as important contextual variation across contexts that determines how features of the agricultural mosaic shape rural out-migration patterns.

\section{Review of the Literature}

Because of the differences in the economy and nature of agriculture across the two nations, Nepal and Thailand represent interesting case studies of the influence of agriculture on migration. Thailand is the more economically developed country, and is a major world exporter of rice, rubber, sugar cane, and cassava. It has been experiencing a significant transition in its economic base from agriculture to manufacturing and service, especially since the 1980s. In 1994 (the start of the Thailand time series data used here), the World Bank (2008) indicated that Thailand's gross national income (GNI) per capita (expressed in terms of purchasing power parity) was $\$ 4,310$, compared to Nepal's GNI of only $\$ 690$ in 1996 (the start of the Nepal time series). Thailand's economy grew substantially in the decades prior to the 1997 Asian financial crisis, averaging around 9 percent annual growth in its gross domestic product (GDP) between 1985 and 1995 (Bello, Cunningham, and Li 1998). While a declining share of the labor force was employed in farming over time, owing largely to the substitution of agricultural inputs for land and labor, the agricultural sector has seen improvements in productivity, increasing commercialization, and a growth in specialized professional farming (Leturque and Wiggins 2011). 
Nepal's economic situation is less favorable, and domestic employment opportunities are limited. Nepal is one of the least developed countries in South Asia (Kollmair et al. 2006) and has one of the world's highest rates of agricultural employment (Graner 2001). Economic growth is slow relative to Thailand, with an average annual increase in GDP of roughly 5 percent around the time of our study (World Bank 2008). Agriculture remains a substantial part of the national economy, and subsistence farming constitutes the principal source of food, income, and employment for the majority of the population (Savada 1991; World Bank 2012). Agriculture is carried out mainly by small farmers, and is characterized by unequal distribution of landholdings, low productivity, and rampant seasonal unemployment (Nepal and Thapa 2009). Given the different macrosocietal contexts in which they are embedded, it is likely that agricultural push factors behave differently in these two settings. In what follows, we consider theoretical perspectives related to migration push factors and we reflect on how they differ across the two nations.

Contemporary explanations for migration push factors focus on household-level models. One of these theories, known as the new economics of labor migration, holds that migration is part of a household strategy aimed at overcoming market imperfections in rural areas (Taylor, Rozelle, and de Brauw 2003). Having limited access to capital and insurance, rural households send migrants to act as target earners who seek other, and different, employment opportunities to diversify the household's income flow and create opportunities for investment in new production technologies. These migrants are usually temporary, and many eventually return when their earnings target is met.

The sustainable livelihoods framework, a related perspective, views households as engaging in a livelihood diversification process involving a mix of farming, off-farm employment, and nonfarm labor that perpetuates their survival and improves their standard of living (Ellis 1998). To satisfy their livelihood goals, households mobilize a combination of human, natural, physical, social, and cultural capital (Bebbington 1999). While not commonly applied to the study of migration determinants, the perspective is relevant, in that it focuses explicitly on agricultural activities, and views migration as one form of nonfarm labor that grants households access to remittance money.

These two perspectives identify a common set of underlying motivations for migration related to two considerations: risks and amenities. Migration is a way of mitigating risk, which represents a positive incentive for movement. Amenities, however, can either discourage migration, in the event that a household possesses some asset that makes 
migration less appealing, or encourage it, in the event that movement enables the household to develop an existing amenity or acquire a new asset. In examining migration determinants associated with agriculture, we attempt to link more proximal causes, such as landholdings size, land tenure, farm portfolio, and use of inputs, to efforts by households to organize their livelihood activities according to these two underlying motivations. We also consider how particular aspects of agriculture within our study settings are related to migration patterns.

While several features of household farming potentially affect outmigration, thus far the size of landholdings has received the most attention in the migration literature. Household landholdings are viewed in three distinct ways that produce different predictions (VanWey 2005). First, land provides employment, which reduces the incidence of migration (Zhao 1999). Second, land is a form of investment, which encourages short-term migration to earn money to finance agricultural inputs and to expand or improve existing landholdings (Jokisch 2002). Third, land is a measure of relative deprivation, which encourages households to send migrants to generate income and equalize wealth within their peer group (Stark and Taylor 1989).

We regard employment and investment opportunities as types of amenities, albeit ones having opposite influences on migration. Empirically, many studies find that landholding size has a negative effect on migration, which is consistent with the view of land as a form of employment (Gray 2009; Rozelle, Taylor, and deBrauw 1999). Further research suggests that the effect of landholding size can be different for small landholders, who struggle to eke out an existence with limited resources for crop cultivation and animal grazing, compared to large landholders, who face fewer limitations (VanWey 2003). Furthermore, its effect differs across contexts and different types of migration patterns. In a comparative study of Thailand and Mexico, VanWey (2005) found that in the former (particularly in the internal migration context), landholdings were negatively related to migration for small landholders, but positively for larger landholders. This result is consistent with the view of land as a form of investment, which creates an incentive to migrate. In Mexico, landholding had a similar effect to that in Thailand, at least for international migration. However, it had a negative effect on internal migration, a view more consistent with land as employment.

Given the apparent differences across contexts, we expect the landholding size effect to differ in the Thai and Nepalese settings as well. Thailand has considerably more agricultural land per person than most Asian countries (Leturque and Wiggins 2011). In contrast, Nepal has a 
high degree of land fragmentation, and highly unequal distribution of land resources (World Bank 2012). Therefore, we believe that landholdings will be a more significant driver of migration in Nepal than in Thailand, given its greater availability in the latter compared to the former.

Other agricultural factors potentially influencing migration include land tenure. It is clear from the migration literature that tenure is related to in-migration (e.g., Muriuki et al. 2011), although studies of its effect on out-migration are less common. ${ }^{1}$ Recent research in rural China offers some insights into the tenure-migration nexus. Mullen, Grosjean, and Kontoleon (2011) find that land insecurity reduces migration. In rural China, migration siphons off household labor, increasing the risk of land expropriation under collective farming arrangements, thus lowering the incentive to migrate. However, tenure operates differently depending on whether households have the right to rent out land. In settings where land rental rights are more established, tenure security has a positive effect on migration, but it has the opposite effect in areas where rental rights are limited. This is because households losing labor because of migration can offset some of these losses by renting land without the fear of expropriation.

We argue that in settings such as Thailand and Nepal, where land is held by individual households rather than by larger collectives, and land rental rights are not restricted, land insecurity should increase migration, because it represents a form of risk. Without secure private land claims, short-term production strategies emerge, leading to unsustainable agricultural practices resulting in soil degradation and erosion, which should increase the incentive to migrate (Amacher et al. 1998). Secure tenure is a form of amenity that makes investing in effective farming more tenable, thus lowering the incentive to migrate. Accordingly, we believe tenure should be a more significant driver of migration in Nepal than in Thailand because of such factors as greater tenancy restrictions, high land fragmentation, and absentee landlordism (World Bank 2012).

Agricultural households also face risks associated with the diversity of their farming practices, or farming portfolio. Used in reference to agriculture, portfolio refers to the mix of horticulture and animal husbandry activities households use to fulfill economic functions (Dixon, Gulliver, and Gibbon 2001). As households raise livestock and plant a variety

\footnotetext{
${ }^{1}$ Some studies include measures such as the "amount of land owned" as a determinant of migration (e.g., VanWey 2003), but it is difficult from these studies to determine whether tenure or landholding size is driving results.
} 
of staple, subsistence, and cash crops, they lower their susceptibility to risks from threats such as crop failures, droughts, blights, famines, and downturns in crop prices (Pangali 1997). Being less risky, a diverse portfolio of activities should decrease the incentive to migrate. Cash crops, in particular, represent an important amenity because they enable households to raise money locally, hence lowering the incentive to migrate. Likewise, raising livestock also brings capital gains from sale, and this reduces the migration incentive. Furthermore, animal husbandry makes it particularly difficult to send seasonal or other types of circular migrants, since, unlike crops, animals require a year-round commitment.

Perhaps because of the small landholdings found throughout parts of Nepal, farmers grow a variety of crops throughout the year, and hence have a fairly diverse farming portfolio. In Thailand, growing multiple crops per year is common only in the central region, where irrigation is more widely used. Aside from select areas of the country where rubber, sugar cane, and cassava are harvested, most Thai farmers rely on a single annual rice crop. Unfortunately, low prices for rice on the world market in the 1980 s and 1990 s made rice farming less profitable, triggering movement out of farming (Leturque and Wiggins 2011). However, since the 1970s, an export market developed for cassava, a low-cost animal feed, which made this form of cash cropping profitable, especially in the northeast region, where our Thai study site is located. We believe that relying on only a single crop (such as rice) is riskier than having a diverse crop portfolio, and this should be a more significant driver of migration in Thailand, relative to Nepal. We also believe that cash crop cultivation should be more significant in discouraging migration in Thailand as well.

Agricultural inputs are another potential driver of migration, and represent further forms of amenities. While the amount of farm yield is negatively affected by soil fertility or salinity, agricultural inputs such as fertilizers, herbicides, and irrigation pumps can offset the effects of poor soil quality, making farming more productive, hence lowering the incentive to migrate. Especially in parts of Asia where rice, a heavily waterdependent crop, is widely grown (Dawe 2005), irrigation pumps are a particularly important input. However, mechanized inputs, such as tractors, are also important because they serve to replace lost labor or reduce labor demand more generally, which should increase the migration incentive.

In Thailand, many aspects of agriculture are mechanized, such as the use of four- and two-wheeled tractors for tilling, pumps used for irrigation, and mechanical devices used for threshing. With changes in the 
economy, agricultural machines are becoming more important in farm operations, and the local dealers and retailers are well positioned to fulfill farmers' needs for equipment and parts (Thepent 2012). In Nepal, animal power is the main source of power for agriculture, although use of machines is more concentrated in the Terai region (Shrestha 2012) where the Chitwan study site is located. Because of such factors as high interest rates for credit to purchase machines, lack of awareness about their benefits, and high taxes on imported agricultural equipment, mechanization of agriculture is less prevalent in parts of Nepal. Thus, we believe that agricultural inputs will be a more significant driver of migration in Thailand than in Nepal.

\section{Setting}

Having discussed some common agricultural influences on migration and differences across settings, we now examine particular features of our study settings. Both Nang Rong and Chitwan are postfrontier regions settled after the 1950 s. Both settings remained relatively isolated until major highways were built linking them to other parts of their respective countries.

Nang Rong is located in Buriram Province in northeast Thailand, near the Cambodian border. The northeast is a remote and highly agricultural region in which rural poverty is widespread (Leturque and Wiggins 2011). The availability of ambiguously titled land for clearing brought waves of settlers into the region until the closing of the frontier in the 1970s (Entwisle et al. 1998). The predominant subsistence crop is lowland paddy rice, which relies on water from seasonal monsoon rains. The near absence of mechanized irrigation allows for only one annual crop. Ecological conditions there are not ideally suited to farming, as soils are sandy and only modestly fertile and variation in monsoon rains makes wetland rice growing highly uncertain (Parnell 1988). The dominant cash crop is cassava (Curran 2005), which needs little water and can be grown even during droughts. Other upland crops include corn and sugarcane, which are not part of the local diet. Farmers also raise cattle, pigs, chickens, and other animals, and they cultivate small vegetable gardens. Some of the vegetables from these gardens are sold in local markets.

During the 1980s and 1990s, Thailand's economic boom fueled labor migration (Warr and Nidhiprabha 1996). Rural-to-urban migration became more common than the historically more prevalent pattern of marriage-related rural-to-rural migration (Chamratrithirong et al. 1995). Most of this rural-to-urban migration was to Bangkok and the 
eastern seaboard (a development zone southeast of Bangkok). Migration abroad is uncommon, and usually involves moving to other Asian countries. For men, migration can be associated with military conscription and ordination as a Buddhist monk, both of which require relatively short-term commitments.

Chitwan Valley is located in the Terai region, a fertile area with rich soils and high agricultural productivity in south central Nepal, near the Indian border. During the 1970s, a program of malaria eradication and allocation of newly cleared land brought an influx of migrants from the hills, neighboring districts, and other parts of Nepal (Barber et al. 1997; Shrestha, Velu, and Conway 1993). Most land in Chitwan is devoted to agriculture, with an important distinction made between khet and bari land (Biddlecom, Axinn, and Barber 2005). Khet refers to low wetlands that are the most agriculturally productive and usually used for growing paddy rice. Bari is less agriculturally productive dry upland used to cultivate other subsistence crops such as corn and millet. Farming involves an intensive rotation of three annual crops, with rice being the most important. Residents depend on successful field cropping for much of their subsistence needs, but also supplement agriculture with a mix of animal husbandry and gathering of forest resources, such as firewood, and fodder for animal feed (Matthews, Shiavkoti, and Chetri 2000).

Poverty, unemployment, declining natural resources, and a recent Maoist insurgency are major motivations for migration, with India, the Gulf States, the "Tiger" states in Asia, and Europe representing primary international destinations (Seddon, Adhikari, and Gurung 2002; Thieme and Wyss 2005). Internal migration in Nepal is connected to frontier resettlement and the boom in the domestic carpet industry, which subsided by the middle of the 1990s (Graner 2001). Chitwan residents migrate in roughly equal numbers domestically and abroad, with Narayanghat and Kathmandu representing major domestic destinations. Migration differs for men and women. Indeed, women are legally prohibited from migrating to certain locations, such as the Gulf States (Thieme and Wyss 2005).

Marriage migration is common in both settings, and is likely to be short-distance (i.e., within the district), rural-to-rural migration. In Nepal, the most common pattern is for the bride to move in with the groom's family following marriage (i.e., patrilocal postnuptial residence). In northeast Thailand, in contrast, the pattern is matrilocal. However, the behavioral reality is that the couple settles wherever resources are greatest (Chamratrithirong, Morgan, and Rindfuss 1988). 


\section{Statement of the Problem}

Using data from these two settings, we examine agricultural determinants of migration using measures of the size of landholdings, land tenure, farming portfolios, and agricultural inputs. Similarities in findings across settings imply a general pattern, while differences suggest the influence of contextual factors. Following past research, we expect landholding size to have a positive effect on migration if it represents an opportunity for investment, and a negative effect if it creates the potential for employment. We anticipate differences in its effect for large- and smallholder farm systems, with the former using land as an amenity and the latter facing the risk of land scarcity. We also expect the landholding effect to be a more important driver of migration in Nepal, where land availability is more limited. We anticipate secure land tenure to reduce migration, since households with secure holding status ought to provide the best stewardship of it, thus enjoying higher yields. We believe tenure effects will be more significant in Nepal, owing to the greater risks surrounding land ownership in that country.

We anticipate that a diverse crop portfolio should reduce migration because it lowers households' susceptibility to risks associated with growing a single crop (such as rice), including crop failures and price fluctuations. We make similar predictions for animal husbandry. Since it requires a year-round labor commitment and potentially lowers capital constraints through sale of animals, it reduces susceptibility to risk. Where households grow cash crops as a way of generating income, this should reduce migration. Both rice monocropping and sale of cash crops are prominent in Thailand; thus we expect these effects to be more significant drivers there. We have mixed expectations about the use of farm inputs. Because they increase farm yield, thus improving farm productivity, irrigation pumps should reduce the migration incentive. However, tractors should encourage migration, as they lower labor

demand. Agricultural inputs ought to be more significant drivers in Thailand, where they are more prevalent.

\section{Basic Approach}

We develop a series of panel regression models using data from the two study sites. Migration, the dependent variable, is measured as a set of individual-level, multicategory nominal variables. The first variable distinguishes migration by duration and the second by distance. Key independent variables are household-level measures of features of the farm system, including landholding size, land tenure, cropping portfolio, and 
use of agricultural inputs. We include variables affecting migration that are also related to aspects of the farm system as controls. These include measures of migration-specific, human, and physical capital; demographic characteristics; household sociodemographics; and community measures.

To establish a proper time ordering of events, we measure independent and control variables in a baseline year, while we measure migration prospectively, as a change in residence occurring between baseline and a subsequent time. We use a "clean sample" approach, whereby we start with a cohort of young people, age 15-19 (in 1994 for Nang Rong and in 1996 for Chitwan), who are likely to be too young to have migrated at baseline, but old enough to migrate in the period under study. We "followed" these individuals (in the sense that we link their data across time) for a period of six years after baseline (until they are between the ages of 21 and 25) to determine whether a move occurred. Our choice of six years is due to data constraints, as this is the number of years separating data panels in the Nang Rong data. We believe it is a reasonable choice, because it allows sufficient time for most people to migrate.

While we prefer to use a sample of all working-age people, doing so potentially introduces sample selectivity bias. This is because our sampling universe starts with a cross-section of people in a baseline year, and many of those of working age, who are in the prime migratory ages, are likely to have already left. Starting with a sample of people who are too young to migrate reduces this potential problem. Because we follow these cases prospectively for six years, our research design captures a period in the life course when many are beginning to migrate. Indeed, our preliminary research in both settings suggests that migration propensities rise in the teen years and peak around age 20 .

As some young people began migrating earlier, perhaps as young as age 13 (an age when individuals begin migrating independently), this probably introduces some truncation into our sample. To account for this problem, we control for the number of migrations an individual experienced between age at the time of the survey and age 13. Another potential source of sample selectivity is attrition after baseline, as for example when an entire household moves out of the village or neighborhood. In both data sets, we located and interviewed these households, which would normally be lost to follow-up. We thus included them in our analysis. As there are too few to designate as a separate outcome, we treat individuals from these households as migrants. 


\section{Data}

Data for the study come from the Nang Rong Project for Thailand and the Chitwan Valley Family Study for Nepal. Because of space limitations, we omit a detailed description of the data, but more details are available in published sources. ${ }^{2}$ For Nang Rong, we use data from the 1994 and 2000 surveys and an analytical sample of 2,538 individuals. For Chitwan, we use data from the 1996 baseline household and agricultural surveys, neighborhood history calendar, prospective household registry, and land survey with an analytical sample of 876 individuals.

\section{Measures}

Although data from our two study settings were not collected for the purpose of comparative analysis, we took a number of steps in constructing our analysis sample and variable definitions to make them as comparable as possible. We include similar variables in both models and measures use common metrics across settings (e.g., such as hectares).

Two dimensions of migration are measured, and both define migration as a change in residence involving a move outside the sample community (i.e., village or neighborhood) lasting two or more months. The first dimension is a rough measure of circular migration versus long-term migration, and distinguishes between nonmigrants, return migrants, and ongoing migrants. For Nang Rong, information for this measure came from the 1994 and 2000 household survey and 2000 life history calendar. Starting with a sample of young people residing in their sample community, we define nonmigrants as those who did not migrate at any point between 1994 and 2000. Return migrants are those who migrated sometime between 1994 and 2000 (as indicated by changes in residence from their life history calendar), but were residing in their origin village in 2000. Ongoing migrants include those who were migrants in 2000. We acknowledge that this measure of circular migration is imperfect, given that ongoing migrants may have returned any time within the six years without our knowledge. The data do not contain sufficient information to determine this possibility for all migrants; therefore, to maintain comparability across settings we are forced to rely on a comparison of returnees and ongoing migrants, rather than a comparison of circular and noncircular migrants.

\footnotetext{
${ }^{2}$ For Nang Rong, see http://www.cpc.unc.edu/projects/nangrong/ or Rindfuss et al. (2007) and Entwisle et al. (2005); for Chitwan, see http://perl.psc.isr.umich.edu/ or Axinn, Pearce, and Ghimire (1999) and Axinn, Barber, and Ghimire (1997).
} 
Table 1. Percentage Distribution of Migration Status and Distance for Nang Rong, Thailand, in 1994 and Chitwan, Nepal, in 1996.

\begin{tabular}{lrr}
\hline & Chitwan & Nang Rong \\
\hline Status & & \\
$\quad$ Did not migrate & 39 & 27 \\
Return migrant & 14 & 19 \\
Ongoing migrant & 46 & 54 \\
Total & 100 & 100 \\
Distance & & \\
Did not migrate & 39 & 27 \\
Migrated only within district & 28 & 6 \\
Migrated outside district & 33 & 67 \\
Total & 100 & 100 \\
\hline
\end{tabular}

Chitwan: $N=876$; Nang Rong: $N=2,538$.

For Chitwan, we measure migration in an analogous manner using data from the monthly prospective household registry. Table 1 shows that nonmigration is less common in Nang Rong than in Chitwan (39 percent not migrating in the latter to only 27 percent in the former). Return migration is a bit more common in Nang Rong, which may indicate the greater ease of circular movement there due to such factors as transportation, the shorter growing season, or the availability of shortterm employment opportunities in major destinations. Ongoing migration is also more common in Nang Rong.

The second dimension is distance. We divide cases into those persons who did not migrate, those who migrated short distances, and those who migrated long distances. We treat moves within the respective districts as "short-distance" moves, and those outside these regions as "longdistance." Short-distance moves are likely to be marriage related while long-distance moves are probably work related. We note that in terms of geographic size, Chitwan is about three times larger than Nang Rong $\left(769.8 \mathrm{~km}^{2}\right.$ vs. $\left.2,218 \mathrm{~km}^{2}\right)$. Also, Chitwan neighborhoods are smaller geographic units than Nang Rong villages, hence we are more likely to identify short-distance moves in Chitwan than in Thailand. Thus, these measures are not perfectly comparable. Preliminary analysis (not shown in table) indicated that return and ongoing migrants from Nang Rong overwhelmingly migrate outside the district and at a much higher proportion than Chitwan migrants; in Chitwan, returning and ongoing migrants were slightly more likely to move outside the district.

We constructed farming variables from various survey items included in the data sets. For Nang Rong, we asked respondents about characteristics of all land plots owned and used by their household. Specifically, 
interviewers asked them about the size, primary and secondary activity (e.g., rice cultivation, abandoned land), and ownership status of each plot (e.g., owned, rented). For Chitwan, respondents provided information about the amount of bari and khet land that their household used for farming and whether the household owned, sharecropped, contracted out, or farmed either type of land through a tenant arrangement. Households could choose multiple ownership types. Separate survey items also inquired about the amount of khet and bari land used for growing up to four different crop types.

Using these items, we constructed the following measures: (1) overall landholding size, which comes directly from the questionnaire for Nang Rong and combines khet and bari land size for Chitwan; (2) dummy measures of crop portfolio, including whether the household grows only rice, only cash crops, or a combination of crops; ${ }^{3}$ (3) dummy variables for whether the household engages in any of these activities independently; and (4) dummy variables for whether the household owns, mortgages, or sharecrops any land. Some households have multiple land plots, and therefore may have a variety of types of ownership status. Also, rented land in Nang Rong is usually paid for with in-kind payments of a portion of the crop yield, rather than in cash; therefore, we treat rented land in Nang Rong as akin to sharecropped land in Chitwan.

Table 2 shows that landholding size, on average, is larger in Nang Rong (over 3.5 ha) than in Chitwan (1 ha). ${ }^{4}$ In our statistical models, we used a log transformation to normalize the skewness of landholding size,

\footnotetext{
${ }^{3}$ We also examined diversification in planting crops, raising animals, a combination of both, or neither. Regression results showed no individual or jointly significant effects, so we focus on crop diversity rather than farming diversity in our explanations.

${ }^{4}$ In Thailand, three different metrics are used to measure land unit size: rai, ngan, and wah. In 1994, landholding size data were collected using only a single metric, rai, and there is concern that some respondents may have been reporting in a metric other than rai. To examine this possibility, we compared landholding sizes across the 1994 and 2000 panels for a cohort of households aggregated to the 1994 household definition in 2000. In the 2000 survey, we asked respondents to indicate the size of each parcel and to tell the interviewer specifically which metric they were using, and reported values were comparable to those derived from a 2000 Geographic Information Systems database that was collected in an entirely different manner. We found an average difference in landholding of just under 1 rai (0.16 ha) across waves (i.e., it was smaller in 1994 than in 2000), but the differences were as high as 32 ha for a few households. For the middle 50 percent of the distribution, values were comparable. Some of this difference may be due to the nature of the comparison we used (i.e., land that was owned and used in 2000 to land that was owned in 1994, which excludes land owned in 2000 but rented out to others). We estimated our final models with the landholding size variable omitted to see if our results were robust. The results (available on request) were comparable and did not change our basic conclusions. Nevertheless, we caution that the effect of the landholding size coefficient may be biased in our final models because of possible measurement error.
} 
Table 2. Descriptive Statistics for Individuals Age 15-19 in Nang Rong, Thailand, in 1994 and Chitwan Valley, Nepal, in 1996.

\begin{tabular}{|c|c|c|c|c|}
\hline \multirow[b]{2}{*}{ Variable } & \multicolumn{2}{|c|}{ Chitwan } & \multicolumn{2}{|c|}{ Nang Rong } \\
\hline & Mean & SD & Mean & SD \\
\hline Size of household landholdings (ha) & 1.01 & 0.94 & 3.57 & 3.63 \\
\hline Bari landholdings (ha) & 0.30 & 0.42 & - & - \\
\hline Khet landholdings (ha) & 0.71 & 0.79 & - & - \\
\hline \multicolumn{5}{|l|}{ Household landholding status } \\
\hline Owns any land & 0.93 & 0.26 & 0.93 & 0.25 \\
\hline Sharecrops any land & 0.25 & 0.43 & 0.18 & 0.38 \\
\hline Mortgages any land & 0.12 & 0.32 & 0.04 & 0.20 \\
\hline \multicolumn{5}{|l|}{ Crop portfolio } \\
\hline Grows rice only & 0.33 & 0.47 & 0.70 & 0.46 \\
\hline Grows cash crops only & 0.04 & 0.20 & 0.01 & 0.10 \\
\hline Grows no crops & 0.11 & 0.32 & 0.08 & 0.26 \\
\hline Grows combination of crops & 0.51 & 0.50 & 0.21 & 0.41 \\
\hline \multicolumn{5}{|l|}{ Crops grown } \\
\hline Grows rice & 0.65 & 0.48 & 0.91 & 0.28 \\
\hline Grows cash crops & 0.31 & 0.46 & 0.17 & 0.38 \\
\hline Grows other crops & 0.42 & 0.49 & 0.05 & 0.23 \\
\hline \multicolumn{5}{|l|}{ Animal husbandry } \\
\hline Number of cattle & 1.34 & 1.70 & 1.62 & 4.60 \\
\hline Number of buffalo & 1.79 & 1.68 & 2.26 & 2.77 \\
\hline Number of pigs & 0.08 & 0.43 & 0.66 & 3.10 \\
\hline \multicolumn{5}{|l|}{ Farm mechanization } \\
\hline Household uses irrigation pump & 0.12 & 0.32 & 0.17 & 0.38 \\
\hline Household uses tractor & 0.70 & 0.46 & 0.60 & 0.49 \\
\hline \multicolumn{5}{|l|}{ Demographic characteristics of individual } \\
\hline Gender (male) & 0.44 & 0.50 & 0.52 & 0.50 \\
\hline Age (in years) & 16.86 & 1.37 & 16.79 & 1.41 \\
\hline Marital status (ever married) & 0.14 & 0.35 & 0.07 & 0.26 \\
\hline Any of own children in household & 0.05 & 0.22 & 0.03 & 0.18 \\
\hline \multicolumn{5}{|l|}{ Educational attainment } \\
\hline Less than six years of education & 0.30 & 0.46 & 0.06 & 0.24 \\
\hline Six years of education & 0.12 & 0.33 & 0.59 & 0.49 \\
\hline Over six years of education & 0.58 & 0.49 & 0.35 & 0.48 \\
\hline \multicolumn{5}{|l|}{ Ethnicity } \\
\hline Upper-caste Hindu & 0.52 & 0.50 & - & - \\
\hline Hill Tibeto-Burmese & 0.14 & 0.34 & - & - \\
\hline Lower-caste Hindu & 0.10 & 0.30 & - & - \\
\hline Newar & 0.07 & 0.25 & - & - \\
\hline Terai Tibeto-Burmese & 0.18 & 0.38 & - & - \\
\hline Migrations since age 13 (count) & 0.24 & 0.49 & 0.20 & 0.63 \\
\hline \multicolumn{5}{|l|}{ Other household characteristics } \\
\hline \multicolumn{5}{|l|}{ Language spoken in the household } \\
\hline Thai (Korat and Central) & - & - & 0.77 & 0.42 \\
\hline Khmer & - & - & 0.07 & 0.26 \\
\hline Lao & - & - & 0.16 & 0.37 \\
\hline \multicolumn{5}{|l|}{ Parents' residence with household } \\
\hline Both parents reside & 0.75 & 0.43 & 0.78 & 0.42 \\
\hline Only one parent resides & 0.09 & 0.29 & 0.14 & 0.34 \\
\hline Neither parent resides & 0.16 & 0.37 & 0.09 & 0.28 \\
\hline
\end{tabular}


Table 2. Continued

\begin{tabular}{|c|c|c|c|c|}
\hline \multirow[b]{2}{*}{ Variable } & \multicolumn{2}{|c|}{ Chitwan } & \multicolumn{2}{|c|}{ Nang Rong } \\
\hline & Mean & SD & Mean & SD \\
\hline Other members age 14 or younger (count) & 1.95 & 1.90 & 1.07 & 1.06 \\
\hline Other members age $15-55$ (count) & 1.86 & 1.86 & 1.17 & 1.19 \\
\hline Other members age 56 or older (count) & 0.22 & 0.52 & 0.23 & 0.51 \\
\hline Members with migration experience (count) & 0.80 & 1.04 & 0.40 & 0.68 \\
\hline \multicolumn{5}{|l|}{ Household wealth distribution position } \\
\hline Bottom tercile & 0.25 & 0.43 & 0.18 & 0.39 \\
\hline Middle tercile & 0.37 & 0.48 & 0.38 & 0.49 \\
\hline Top tercile & 0.38 & 0.49 & 0.44 & 0.50 \\
\hline \multicolumn{5}{|l|}{ Neighborhood and village variables } \\
\hline Undeveloped or common land in neighborhood $(\%)$ & 1.17 & 5.26 & - & - \\
\hline Forest land in 3-km buffer $(\%)$ & - & - & 16.00 & 5.05 \\
\hline Time since obtaining electicity (years) & 4.01 & 6.21 & 9.03 & 4.43 \\
\hline Distance of district town $(\mathrm{km})$ & 13.78 & 6.59 & 12.90 & 5.18 \\
\hline
\end{tabular}

Chitwan: $N=876$; Nang Rong: $N=2,538$.

$\mathrm{SD}=$ standard deviation .

as well as several other measures. ${ }^{5}$ In the aggregate, Chitwan households have more khet landholdings ( 0.71 ha, on average) than bari landholdings (0.30 ha, on average). Almost all households own some land (over 90 percent in both settings), although sharecropping and mortgaging is more common in Chitwan than in Nang Rong. Crop diversification also is more common in Chitwan, perhaps because of the more intensive pattern of cropping found there. While the majority of households in Nang Rong (70 percent) grow rice alone, far fewer households do so in Chitwan (33 percent). Over half of Chitwan households grow a combination of crops, compared to only 21 percent of Nang Rong households. In both settings, growing cash crops alone is uncommon. Of the overall proportion growing crops, almost two thirds of Chitwan households grow rice, compared to 91 percent of Nang Rong households. Under a third of Chitwan households grow any cash crops, compared to 17 percent of Nang Rong households.

We also include measures of the number of cattle, buffalo, and pigs owned by the household. Buffalos are traditionally used as draft animals in these settings, while pigs and cattle are used for consumption and sale. For both settings, data for these measures come from specific survey items about these animals. The number of animals of all types is higher in Nang Rong than in Chitwan, and the difference is especially pronounced for pigs. To measure the use of farm inputs and mechanization,

\footnotetext{
${ }^{5}$ Many of the measures we transformed had minimum values of 0 , so we added unity to these measures before taking their natural log.
} 
we use household reports of use of irrigation pumps or tractors. The tractor measure includes both large vehicular tractors and small walking tractors (similar to gasoline-fueled rototillers used in developed countries). In both settings, smaller walking tractors are more common than larger riding tractors. Surprisingly, tractor use is slightly more common in Chitwan (70 percent to 60 percent), although Nang Rong households are more likely to use irrigation pumps (17 percent to 12 percent).

We include controls at the individual, household, and community level. Individual controls include measures of human capital variables (i.e., education and age), ethnicity, and demographic characteristics. We measure educational attainment as a series of indicator variables for whether a respondent attained less than six years of education, six years exactly, or more than six years. ${ }^{6}$ Age is measured in years. We measure gender and marital status, respectively, as dummy variables indicating whether a respondent was male or ever married. We also measure ethnicity as a series of dummy variables. For Chitwan we distinguish between upper-caste Hindu, Hill Tibeto-Burmese, lower-caste Hindus, Newar, and Terai Tibeto-Burmese. The upper-caste Hindu and Newar are the most privileged groups; Terai Tibeto-Burmese are indigenous people, some of whom were former jungle dwellers who adopted a sedentary farming lifestyle in the 1950s. In Nang Rong, we distinguish ethnicity according to language spoken at home, with categories including Thai (i.e., Central Thai, Thailand's official language, and Korat Thai, the more prevalent northeastern dialect considered a mix of Thai and Lao), Lao (the language of the original inhabitants of the region), and Khmer (the language spoken in neighboring Cambodia). ${ }^{7}$ As mentioned earlier, we also include a measure of the focal individual's previous migration experience.

At the household level, we control for potential migrant network connections, wealth, and demographics. To account for possible social network influences, we follow prior research (Kandel and Massey 2002) and use the number of household members having migration experience prior to baseline. For wealth, we use principal components analysis to construct an index, based on the household's ownership of consumer assets (Filmer and Pritchett 2001; Kolenikov and Angeles 2004). We

\footnotetext{
${ }^{6}$ In contrast to Nang Rong, in which six years of schooling is equivalent to primary education, in Chitwan, five years is the cutoff for primary school education. To test the sensitivity of results to our definition of education, we also estimated our empirical models using a five-year definition. Results (available on request) were comparable across education definitions in both settings. In general, the five-year definition dampened the education effect in both regions, and it had a slight impact on the age effect in Chitwan.

${ }^{7}$ We dropped eight cases designated as "other ethnicity" in Chitwan and six cases of persons speaking Suaie in Nang Rong.
} 
include this measure as a series of dummy variables distinguishing household according to wealth terciles of all sample village households. We also construct demographic counts of the number of household residents age 14 years or younger, 15 to 55, and 56 years or older. Fieldwork in Nang Rong suggests these age cutoffs differentiate the working and nonworking populations. All counts exclude the focal individual as well as his or her parents, spouse, and children, since separate variables for the presence of these family members in the focal individual's origin household are also included in the model.

Community-level variables include the percentage of forest cover located within a 3-km radial buffer around the village center (Entwisle et al. 2005). For Chitwan, we include a measure of the percentage of undeveloped or common land (which includes forest). For both settings, we include measures of the straight-line distance to the nearest district town and the number of years that the community had electricity to gauge the level of development and remoteness.

\section{Analytical Approach}

We use a series of multinomial probit models, estimating two sets of models for both settings. The first model uses a similar specification across settings, which rules out differences in results due to model specification. The second uses a specification that we believe better captures the unique context of each setting. Although these results may be less comparable across settings, they provide insight into which factors may be more important in each region.

Our data have a nested structure: individuals are nested within households, within communities, within countries. Recall that we estimate separate models for Nang Rong and Chitwan, which obviates the need to correct for clustering at the country level. We correct for nonindependence of observations due to clustering within communities and we use heteroskedastically robust standard errors (White 1980). We only correct for clustering at the highest hierarchical level, since past research suggests doing so yields comparable results to models in which the full hierarchical structure is specified (Angeles, Guilkey, and Mroz 2005). ${ }^{8}$ To determine the magnitude of variable effects, we

\footnotetext{
${ }^{8}$ We also conducted sensitivity analyses for differences in results related to choice of clustering level. Specifically, we corrected for clustering at the household, rather than the community, level. Results were nearly identical in terms of the overall pattern of statistical significance to those obtained by correcting for clustering at the community level. We also attempted to model the full three-level structure using the Generalized Linear Latent and Mixed Model (GLLAMM) ado file in Stata. GLLAMM uses a modified Newton Raphson algorithm to maximize likelihood functions. It allows users to specify the number of integer
} 
compute microsimulated predicted probabilities for key variables using model coefficients. We also conduct joint hypothesis tests of "blocks" of key independent variables (e.g., landholding status, crop portfolio, crops grown) to supplement tests of individual parameters. ${ }^{9} \mathrm{We}$ include a Wald chi-square statistic comparing our models to the baseline (i.e., intercept only) model to establish the significance of the overall model; all Wald statistics are significant. We refer to predicted probabilities and outcomes of joint significance tests in the discussion of results.

\section{Results}

Results show that agricultural factors have significant effects on migration, but their effects differ across settings. For Chitwan, land tenure and animal husbandry measures are important (see Table 3). Consistent with our arguments about secure tenure, landownership reduces the likelihood of migrating within the district (relative to not migrating). Predicted probabilities indicate that young people from households owning land are 34 percent less likely to migrate within the district. Joint hypothesis tests suggest that the three landholding status measures are significant predictors of migration within the district. Raising pigs has a negative effect on the likelihood of being a return migrant and on migrating outside the district. A 1 percent increase in the number of pigs decreases the likelihood of return migration by 24 percent and decreases the likelihood of migrating outside the district by 25 percent. A joint hypothesis test of all animal husbandry variables also shows a statistically significant effect.

For Nang Rong, crop portfolio and use of farm inputs are important migration determinants (see Table 4). Growing only rice increases the likelihood of being an ongoing migrant (by about 9 percent) and of migrating outside the district (by about 8 percent). Growing no crops increases the likelihood of being an ongoing migrant and of migrating within the district. All three crop portfolio coefficients are jointly

or mass points to be used for integral or summations involved in the likelihood function. In estimating the model, our strategy was to start with a small number of these points (i.e., 4) and to pass results from this model to subsequent models that gradually use more points (i.e., $8,12,16$, etc.). Using more points would presumably give more reliable parameter estimates, but at the cost of (exponentially) higher computation time. We noticed that the estimates bounced around considerably across model runs (which made us skeptical about their veracity), and computation times were excessive, so we ultimately abandoned this approach.

${ }^{9}$ Joint significance tests involve a likelihood ratio test of nested models that compare a restricted model, which excludes variables of interest, to an unrestricted model, which includes these variables. 


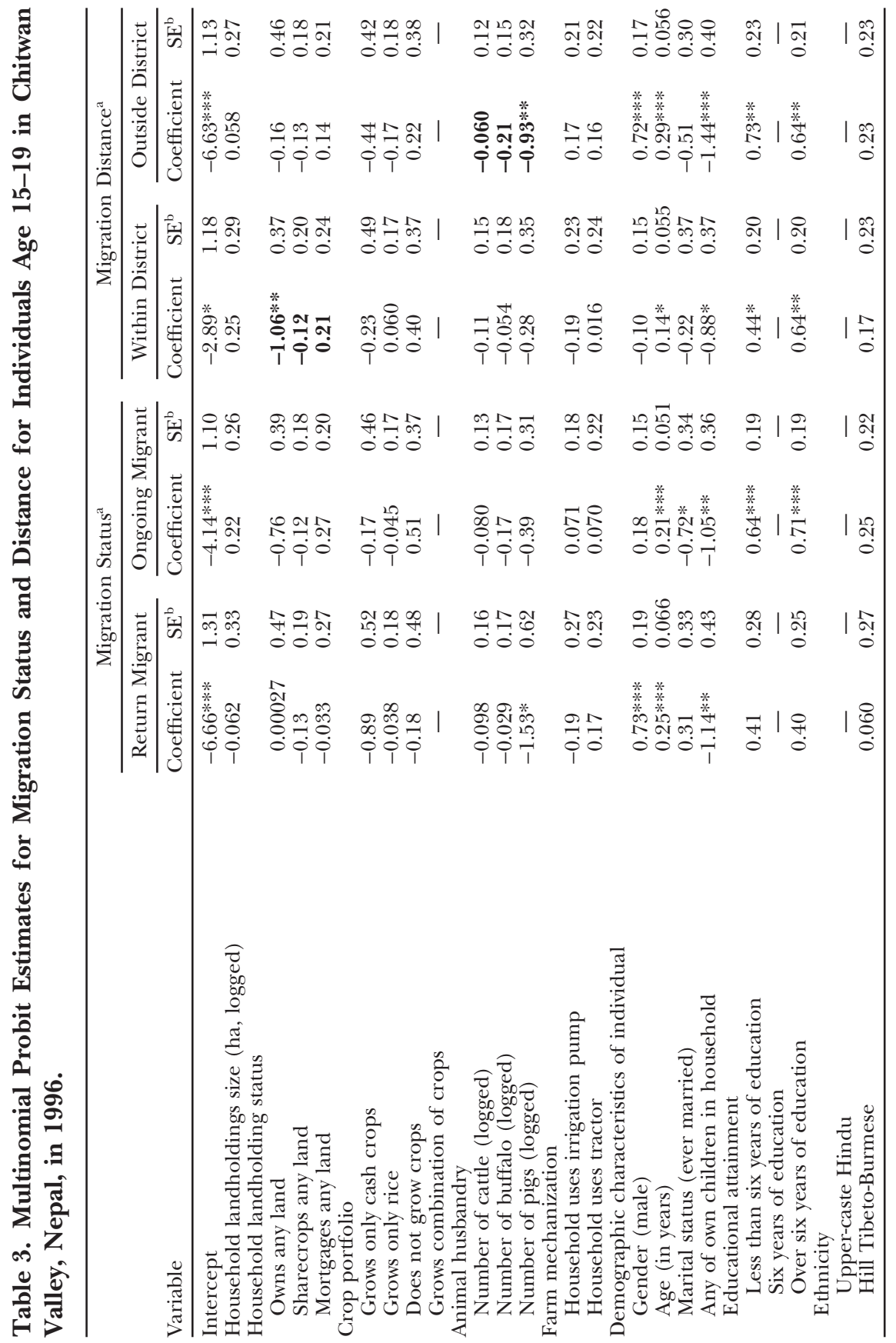


94 Rural Sociology, Vol. 78, No. 1, March 2013

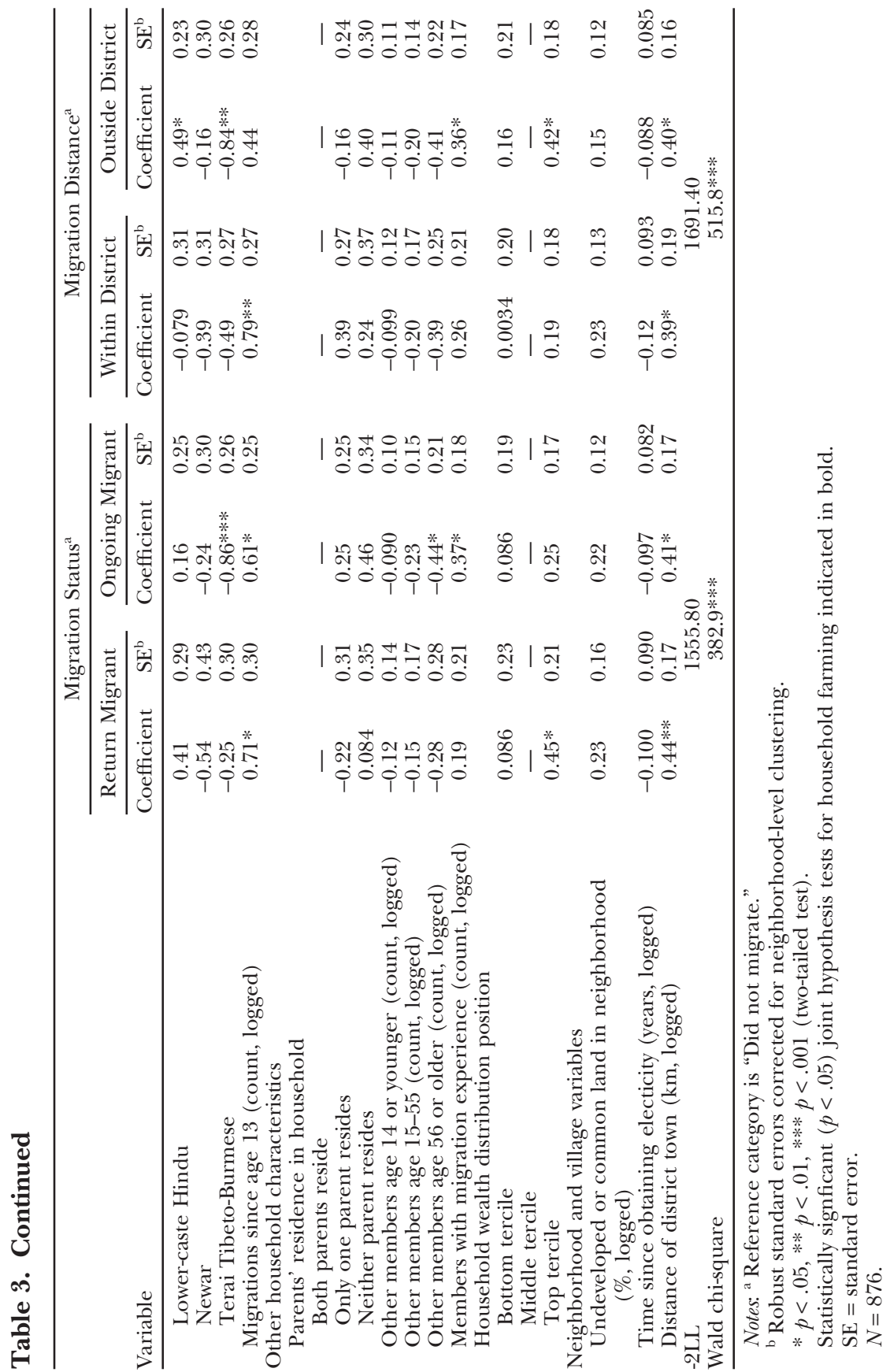




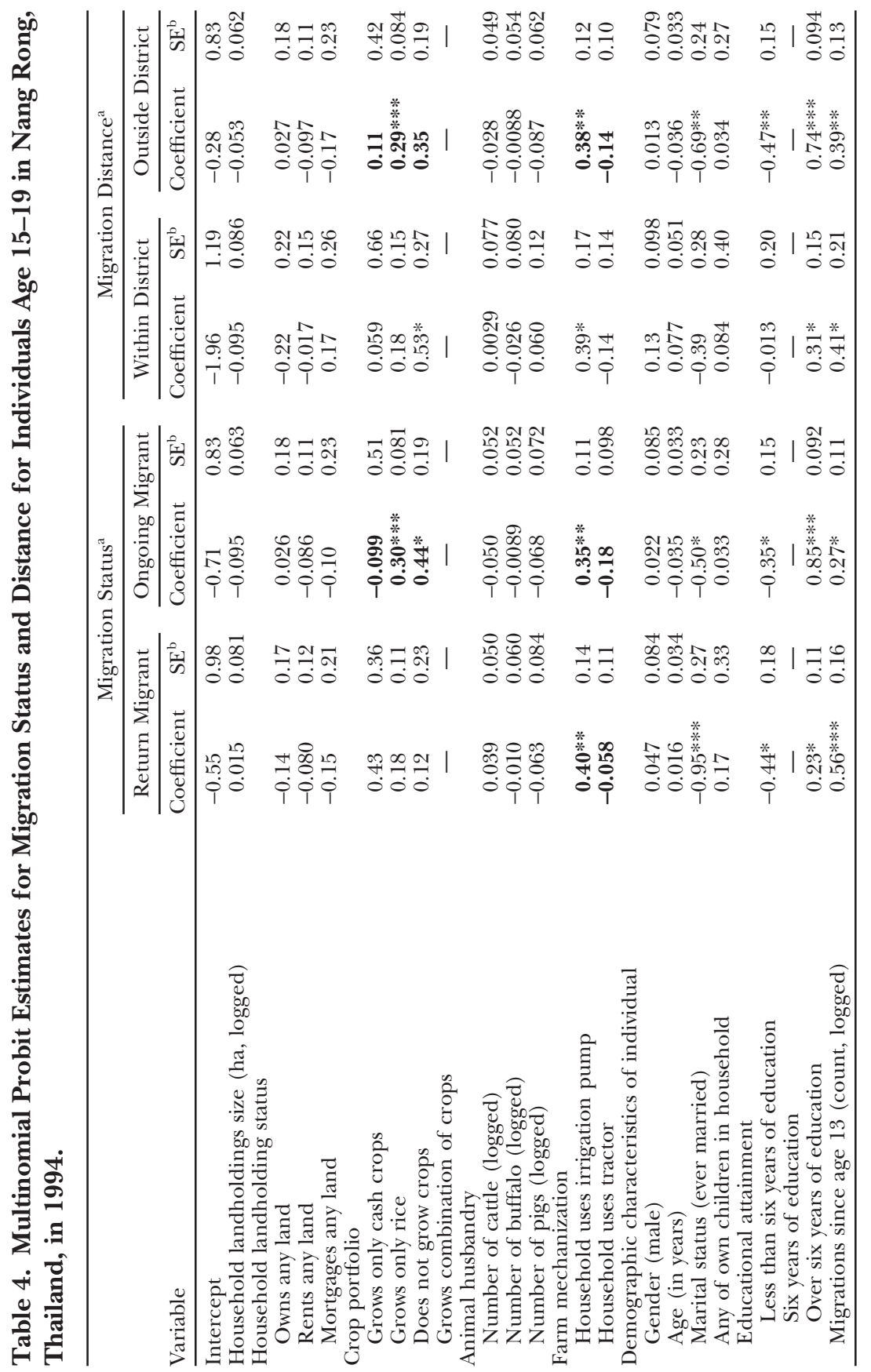




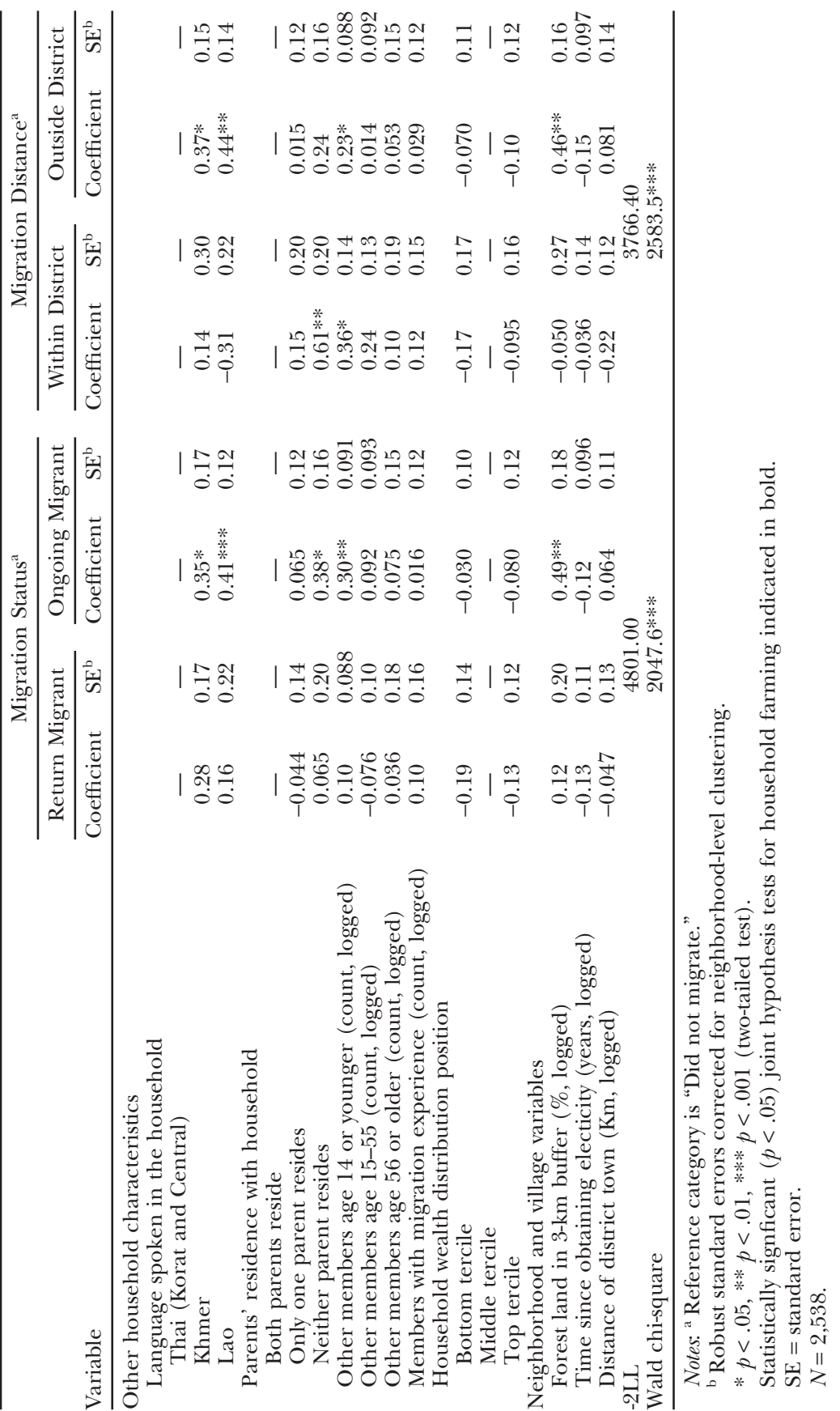


significant in these two contrasts. These effects may be due to the greater susceptibility of risk of growing only a single crop (or no crop) than that of growing a greater variety. Contrary to expectations, using an irrigation pump makes all forms of migration more likely (predicted probabilities range from about 9 to 15 percent, depending on the contrast). The effect is significant for both the likelihood of being an out-migrant and a return migrant, suggesting that it may be linked to circular migration. Perhaps migrants are moving to earn money to help maintain the equipment. Farm mechanization variables are jointly significant in all contrasts, except for movement within the district. Perhaps households involved in pump irrigation and farm mechanization have lower labor demands, which increases the incentive to migrate.

In subsequent models for Chitwan, we divided landholding size into bari and khet, and using a piecewise specification, detected different effects for holdings up to three quarters of a hectare and beyond this level (see Table 5). Results imply a nonlinear effect of bari landholdings on certain migration propensities. For bari holdings up to three quarters of a hectare, the likelihood of all migration types increased with the size of landholdings. However, it was negative for ongoing migration and migration within the district for holdings above three quarters of a hectare. Tests also show that all four coefficients are jointly significant in these contrasts. Perhaps young people from households having a small landholding (i.e., three quarters of a hectare or less) are more likely to migrate because such holdings are insufficient for sustaining successful farming, and thus present a form of risk. The effect of larger landholdings is consistent with the notion that land is a form of amenity, specifically a source of employment. Khet land had a similar effect up to three quarters of a hectare, but only for ongoing migration and migration within the district.

For Nang Rong, we examined the independent effect of growing different crop types (see Table 6 ). ${ }^{10}$ We found that growing any cash crops decreases the likelihood of being an ongoing migrant (by about 12 percent) and of migrating outside the district (by 10 percent). This suggests that cash crops are a form of amenity, and that they provide sufficient capital to allow young people to forgo migration. Joint

\footnotetext{
${ }^{10}$ We also examined nonlinear effects of landholding size by including second- and third-order polynomials. In contrast to VanWey (2003), we did not detect any statistically significant effects. This may be due to the fact that we included measures of many other agricultural variables in our model or because of differences in the age range of our sample.
} 
98 Rural Sociology, Vol. 78, No. 1, March 2013

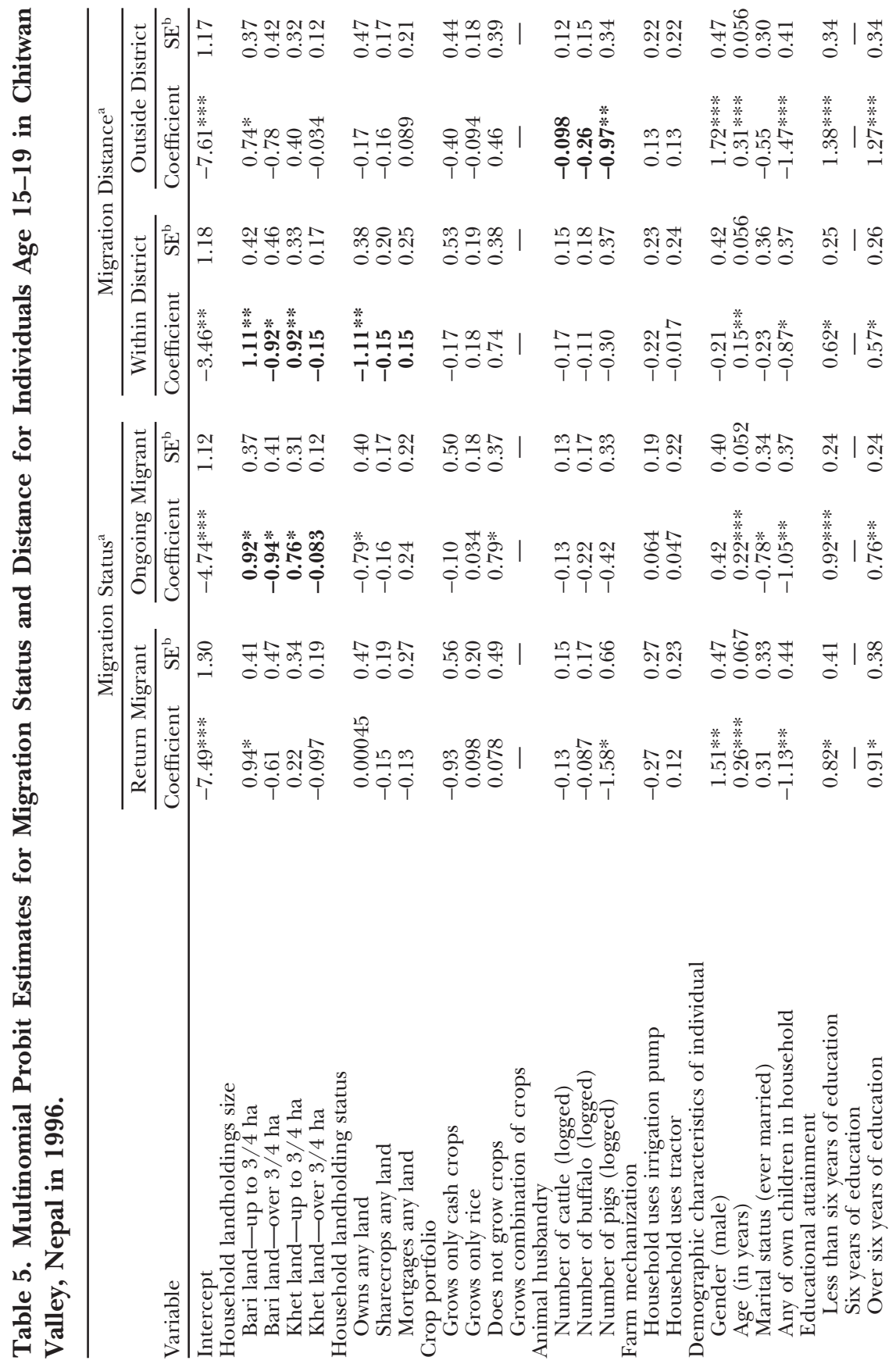




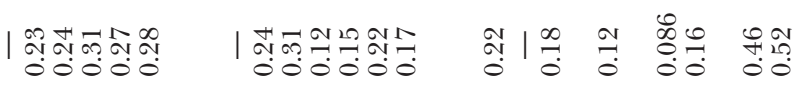

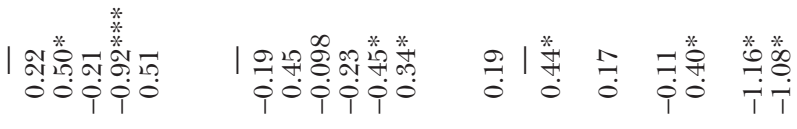

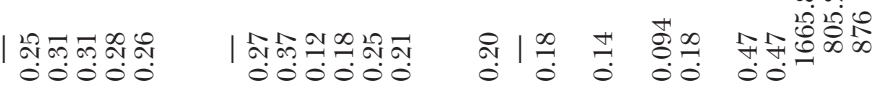

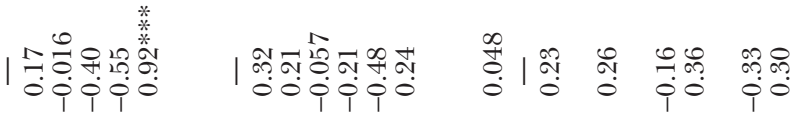

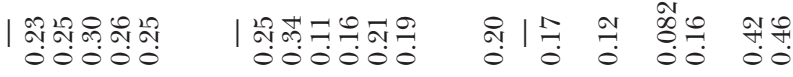

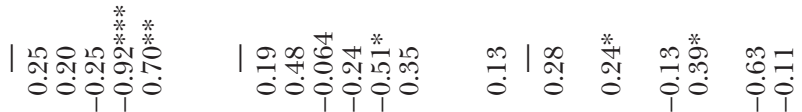

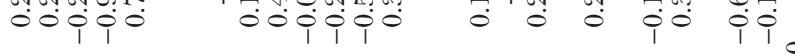

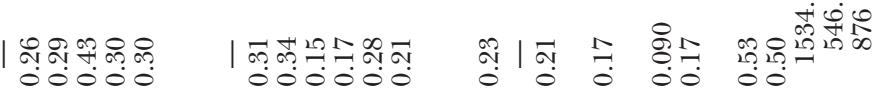

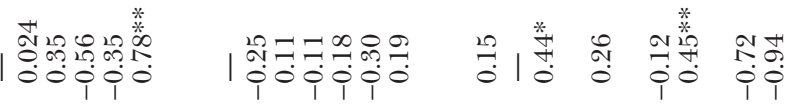


100 Rural Sociology, Vol. 78, No. 1, March 2013

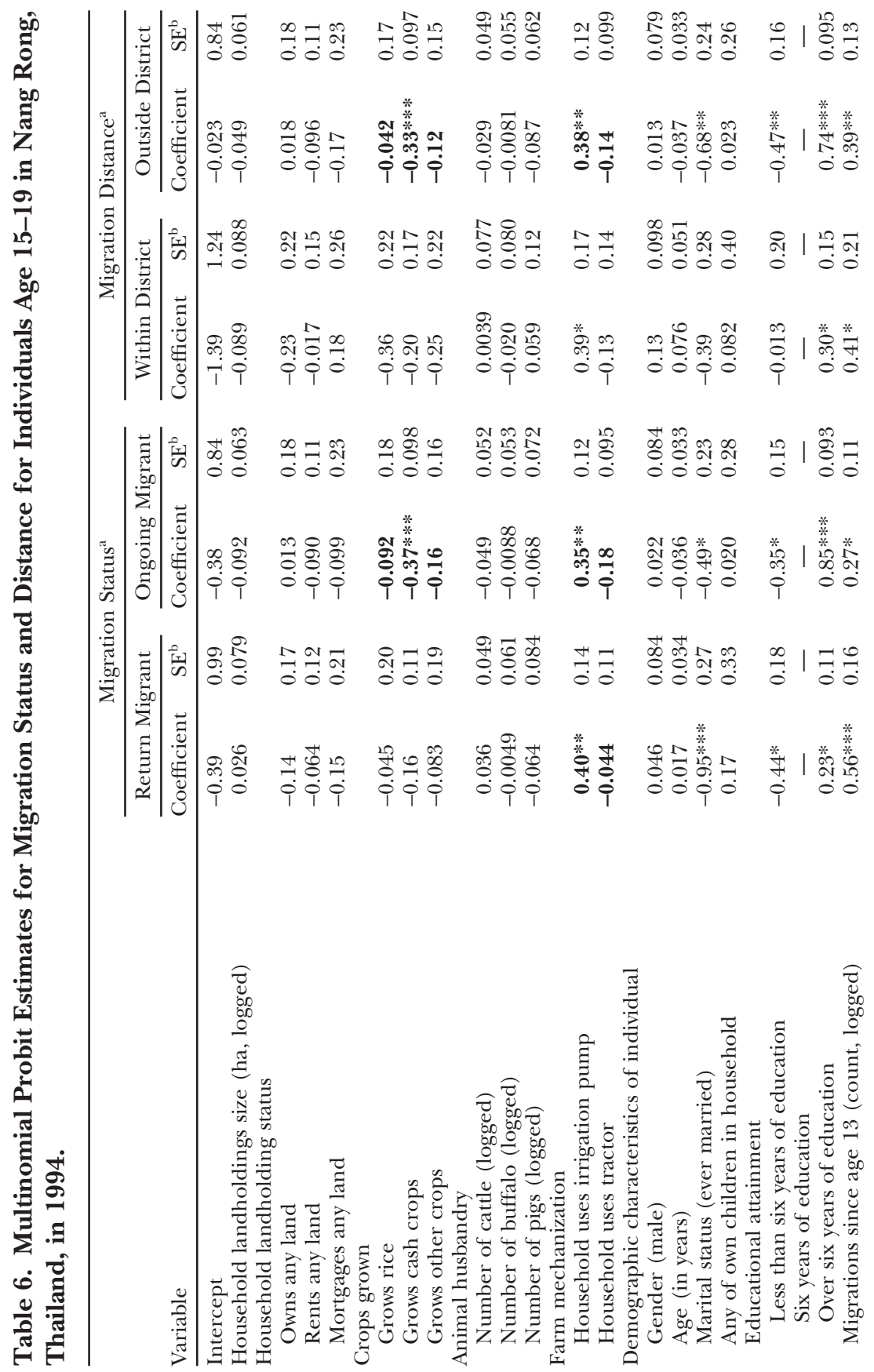




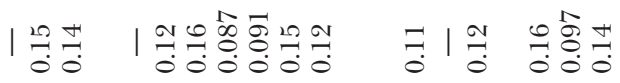

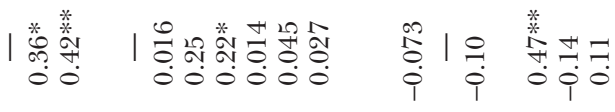

|

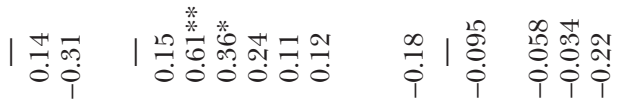

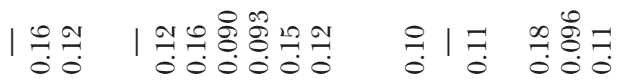

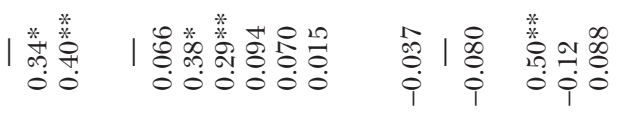

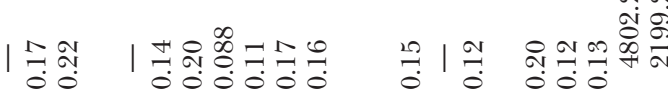

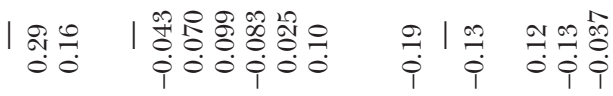

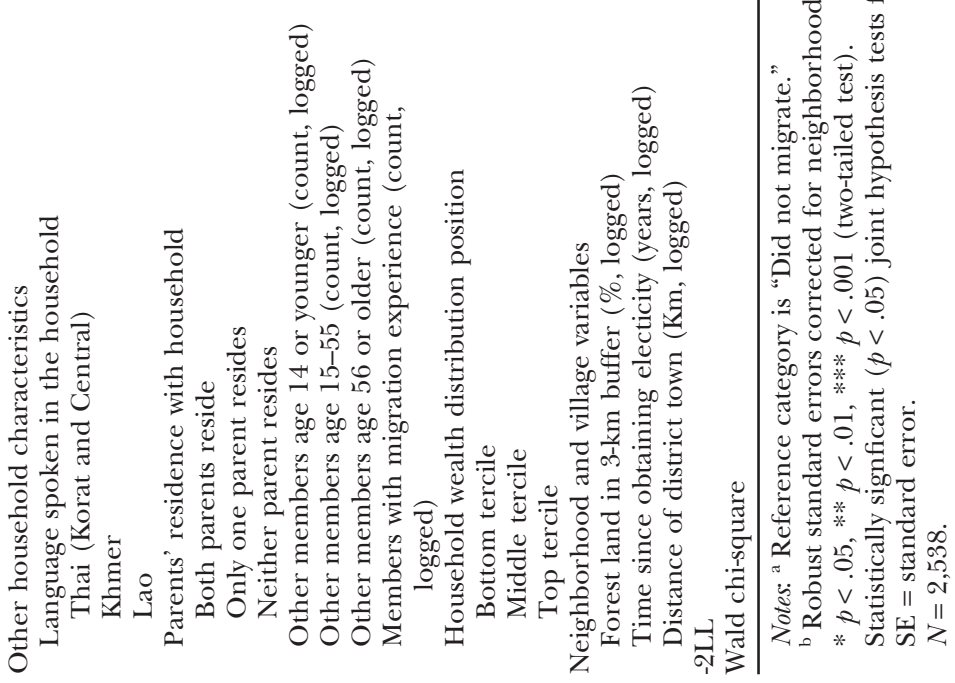


hypothesis tests reveal that all three coefficients measuring the types of crops grown are jointly significant for these two contrasts.

We also find significant results for many control variables, but because of space limitations, we only mention them briefly. In general, we found results for education, migration experience, household wealth, and demographics that are broadly consistent with earlier research. Across settings, there were also differences in the effect of education and household wealth, perhaps suggesting differences in economic pull factors. Moreover, gender differences were more pronounced in Chitwan than in Nang Rong, and were conditional on education in that setting.

\section{Conclusion}

In examining agricultural push factors determining migration in two postfrontier rural settings, Nang Rong Thailand, and Chitwan Valley, Nepal, we consider the effects of a wide variety of agricultural determinants, including land tenure, crop portfolios, animal husbandry, and use of farm inputs. We find that agricultural factors have significant and nontrivial effects on migration patterns in both settings, which are broadly consistent with households' efforts to mitigate risk and take advantage of amenities. However, different factors operate in different settings, suggesting that the nature of risks and amenities differs across settings.

In Nang Rong, households growing only rice, or no crops, are more likely to have migrating young people, especially outside the district, where nonagricultural jobs are easier to find. This finding is likely due to risk factors associated with a lack of diversity in cropping related to such things as variability in rainfall, crop diseases, and the like. We also find that growing particular crops matters, especially cash crops, which make migration outside the district less likely. In a context where an international market for cassava exporting exists, young people from households growing cash crops may have enough access to capital from the sale of these crops to forgo migrating to earn money. Finally, in a context in which most irrigation is rain-fed, and the dominant stable crop heavily depends on water, pump irrigation increases the propensity of almost all forms of migration. Migration may be a way of earning money to help pay for the purchase, maintenance, and operating costs, which, in turn, likely increase farm productivity and contribute to successful farming. Farming can be balanced with a variety of migration strategies, including circular migration, or relatively more permanent movement.

In Chitwan, a context where landholdings are relatively small and tenure more uncertain, young people coming from households with the 
smallest landholdings (i.e., three quarters of a hectare or less) tend to be more likely to migrate (especially short distances) as the size of khet and bari holdings increase. Furthermore, although most households own at least some land, secure tenure (i.e., ownership) lowers the likelihood of migration, particularly within the district. Perhaps insecurity in tenancy and insufficient landholdings makes local wage labor on other households' farms more appealing than migration. As landholding size increases, migration becomes more attractive, and perhaps can be balanced with farming. Young people from households with the largest holdings may have less incentive to migrate, as land provides a form of employment they can use to work on the family farm. Given that three annual crops are grown, it is unsurprising that factors such as diversity in crop portfolio have little effect. However, animal husbandry, especially raising pigs, is a significant deterrent to some forms of migration (especially outside the district), which indicates that raising animals for sale and consumption is a workable option for maintaining a livelihood in an area where landholdings are small.

Our results also inform the broader literature on nonagricultural determinants of migration. Consistent with previous studies, we find that migrants are positively selected for education and prior migration experience in both regions (Kandel and Massey 2002). However, differences in the effects of other characteristics clearly exist across these settings. In particular, gender effects are significantly related to some migration patterns in Chitwan, but none in Nang Rong. In the latter, where both men and women migrate in roughly equal numbers, the contrast to Chitwan, where there are prohibitions on some forms of women's migration, highlights the important role of gender norms in affecting migration outcomes. Also, indicative of differences in economic determinants across settings, migration propensities increase proportionally with distance to the nearest district town in Chitwan. In Nang Rong, the more affluent setting, this factor had no observed effect, perhaps indicating that the region is sufficiently developed so that even remote villages enjoy a high standard of living, which obviates the need to send migrants to meet household livelihood goals. In short, contextual variation plays an important role in influencing migration patterns across settings. While our major contribution is the finding of considerable differences in the effect of agricultural factors, our results are broadly consistent with existing cross-cultural studies suggesting migration determinants generally must be understood in their specific institutional context (Goldstein 1987; Sana and Massey 2005). We acknowledge that other macroeconomic differences across these countries, such as economic development levels, are also driving our results, so push factors alone are 
likely not the only determinants of migration. Future research should endeavor to link individual migration behavior and the broader institutional structure in which it occurs.

We note some limitations to our results. First, our data come from two studies that were not designed for comparative analysis, so some differences across setting (e.g., overall district size and size of community-level entities) may be due to dissimilarities in survey design rather than to true contextual variation. We took steps to create comparable measures and employed a similar analytical strategy to both data sets to minimize this potential limitation. Second, our sample may be truncated due to early migration occurring before baseline, which may introduce selectivity bias. For Nang Rong, we have an earlier data panel from 1984, which we used to examine the characteristics of respondents before they migrated (available on request). We found only small differences between characteristics of those migrating before our baseline year and those included in the sample. Third, our measure of migration duration does not make a clean distinction between circular migrants and "permanent" migrants. The Chitwan data allow us to compare our results to those that use this more ideal measure of duration. Results from this modeling effort were similar to our final results (see Appendix). Noteworthy differences include the effects of khet and bari land exceeding three quarters of a hectare, and the effect of cattle, but these results are small and do not change our basic conclusions.

Despite its limitations, our article makes a valuable contribution to the literature on migration push factors from a cross-national perspective, an understudied area of migration research. Our findings imply that studies of rural out-migration should take into account factors related to many aspects of agriculture, particularly in settings where agriculture is the main economic activity. Findings also suggest that contextual variation plays an important role in differentiating migration patterns that are often assumed to be similar across time and space. 
Appendix. Multinomial Probit Estimates for Migration Status (Circular Migration vs "Permanent" Migration) in Chitwan Valley, Nepal, in 1996.

\begin{tabular}{|c|c|c|c|c|}
\hline \multirow[b]{3}{*}{ Variable } & \multicolumn{4}{|c|}{ Migration Status $^{\mathrm{a}}$} \\
\hline & \multicolumn{2}{|c|}{ Circular Migrant } & \multicolumn{2}{|c|}{ "Permanent" Migrant } \\
\hline & Coefficient & $\mathrm{SE}^{\mathrm{b}}$ & Coefficient & $\mathrm{SE}^{\mathrm{b}}$ \\
\hline Intercept & $-7.04 * * *$ & 1.09 & $-3.14 * *$ & 1.22 \\
\hline \multicolumn{5}{|l|}{ Household landholdings size } \\
\hline Bari land-up to $3 / 4$ ha & $0.92 *$ & 0.37 & $0.93 *$ & 0.43 \\
\hline Bari land-over $3 / 4$ ha & $-0.91 *$ & 0.37 & -0.78 & 0.50 \\
\hline Khet land-up to $3 / 4$ ha & 0.48 & 0.30 & $0.87 *$ & 0.36 \\
\hline Khet land-over $3 / 4$ ha & 0.00092 & 0.13 & $-0.33^{*}$ & 0.16 \\
\hline \multicolumn{5}{|l|}{ Household landolding status } \\
\hline Owns any land & -0.39 & 0.41 & $-0.87 *$ & 0.38 \\
\hline Sharecrops any land & -0.18 & 0.16 & -0.082 & 0.19 \\
\hline Mortgages any land & 0.012 & 0.21 & 0.29 & 0.25 \\
\hline \multicolumn{5}{|l|}{ Crop portfolio } \\
\hline Grows only cash crops & -0.67 & 0.42 & 0.21 & 0.57 \\
\hline Grows only rice & -0.013 & 0.17 & 0.12 & 0.19 \\
\hline Does not grow crops & 0.30 & 0.39 & $0.87 *$ & 0.37 \\
\hline Grows combination of crops & - & - & - & - \\
\hline \multicolumn{5}{|l|}{ Animal husbandry } \\
\hline Number of cattle (logged) & -0.046 & 0.13 & $-0.27 *$ & 0.14 \\
\hline Number of buffalo (logged) & -0.21 & 0.16 & -0.12 & 0.17 \\
\hline Number of pigs (logged) & $-1.01 * *$ & 0.35 & -0.11 & 0.35 \\
\hline \multicolumn{5}{|l|}{ Farm mechanization } \\
\hline Household uses irrigation pump & -0.036 & 0.21 & 0.051 & 0.25 \\
\hline Household uses tractor & 0.15 & 0.21 & -0.094 & 0.23 \\
\hline \multicolumn{5}{|l|}{ Demographic characteristics of individual } \\
\hline Gender (male) & $1.04 *$ & 0.44 & 0.39 & 0.44 \\
\hline Age (in years) & $0.30 * * *$ & 0.050 & $0.13 *$ & 0.060 \\
\hline Marital status (ever married) & -0.083 & 0.33 & $-1.10^{* *}$ & 0.39 \\
\hline Any of own children in household & $-1.24 * * *$ & 0.37 & $-0.81 *$ & 0.40 \\
\hline \multicolumn{5}{|l|}{ Educational attainment } \\
\hline Less than six years of education & $0.98 * *$ & 0.30 & $0.74 * *$ & 0.26 \\
\hline Six years of education & - & - & - & - \\
\hline Over six years of education & $0.99 * * *$ & 0.30 & 0.51 & 0.27 \\
\hline \multicolumn{5}{|l|}{ Ethnicity } \\
\hline Upper-caste Hindu & - & - & - & - \\
\hline Hill Tibeto-Burmese & 0.11 & 0.23 & 0.33 & 0.26 \\
\hline Lower-caste Hindu & 0.11 & 0.24 & 0.44 & 0.28 \\
\hline Newar & -0.43 & 0.31 & -0.079 & 0.31 \\
\hline Terai Tibeto-Burmese & $-0.98 * * *$ & 0.25 & -0.43 & 0.28 \\
\hline Migrations since age 13 (count, logged) & $0.86^{* *}$ & 0.28 & 0.45 & 0.27 \\
\hline \multicolumn{5}{|l|}{ Other household characteristics } \\
\hline \multicolumn{5}{|l|}{ Parents' residence in household } \\
\hline Both parents reside & - & - & - & - \\
\hline Only one parent resides & -0.15 & 0.26 & 0.39 & 0.28 \\
\hline Neither parent resides & 0.15 & 0.34 & $0.79 *$ & 0.36 \\
\hline $\begin{array}{l}\text { Other members age } 14 \text { or younger } \\
\quad \text { (count, logged })\end{array}$ & -0.081 & 0.11 & -0.096 & 0.12 \\
\hline Other members age $15-55$ (count, logged) & -0.19 & 0.15 & -0.30 & 0.18 \\
\hline
\end{tabular}




\section{Appendix. Continued}

\begin{tabular}{|c|c|c|c|c|}
\hline \multirow[b]{3}{*}{ Variable } & \multicolumn{4}{|c|}{ Migration Status $^{\mathrm{a}}$} \\
\hline & \multicolumn{2}{|c|}{ Circular Migrant } & \multicolumn{2}{|c|}{ "Permanent" Migran } \\
\hline & Coefficient & $\mathrm{SE}^{\mathrm{b}}$ & Coefficient & $\mathrm{SE}^{\mathrm{b}}$ \\
\hline $\begin{array}{l}\text { Other members age } 56 \text { or older } \\
\quad \text { (count, logged) }\end{array}$ & -0.33 & 0.22 & $-0.78 * *$ & 0.25 \\
\hline $\begin{array}{l}\text { Members with migration experience } \\
\text { (count, logged) }\end{array}$ & 0.32 & 0.18 & 0.25 & 0.21 \\
\hline \multicolumn{5}{|l|}{ Household wealth distribution position } \\
\hline Bottom tercile & 0.25 & 0.21 & -0.023 & 0.20 \\
\hline Middle tercile & - & - & - & - \\
\hline Top tercile & $0.40^{*}$ & 0.17 & 0.24 & 0.19 \\
\hline \multicolumn{5}{|l|}{ Neighborhood and village variables } \\
\hline $\begin{array}{l}\text { Undeveloped or common land in } \\
\text { neighborhood }(\%, \text { logged })\end{array}$ & $0.29 *$ & 0.14 & 0.14 & 0.14 \\
\hline $\begin{array}{l}\text { Time since obtaining electicity } \\
\text { (years, logged) }\end{array}$ & -0.15 & 0.086 & -0.099 & 0.088 \\
\hline Distance of district town $(\mathrm{km})$ & $0.46^{* *}$ & 0.16 & 0.27 & 0.18 \\
\hline \multicolumn{5}{|l|}{ Interaction terms } \\
\hline Male $\times$ Less than six years of education & -0.71 & 0.46 & -0.62 & 0.46 \\
\hline Male $\times$ Over six years of education & -0.52 & 0.48 & -0.26 & 0.50 \\
\hline$-2 \mathrm{LL}$ & \multicolumn{4}{|c|}{1611.00} \\
\hline Wald chi-square & \multicolumn{4}{|c|}{$579.3 * * *$} \\
\hline
\end{tabular}

Notes: ${ }^{a}$ Reference category is "Did not migrate."

${ }^{\mathrm{b}}$ Robust standard errors corrected for neighborhood-level clustering.

$* p<.05, * * p<.01, * * * p<.001$ (two-tailed test).

$\mathrm{SE}=$ standard error.

$N=876$

\section{References}

Amacher, Gregory S., Wilfrido Cruz, Donald Grebner, and William Hyde. 1998. "Environmental Motivation for Migration: Population Pressure, Poverty, and Deforestation in the Philippines." Land Economics 74(1):92-101.

Angeles, Gustavo, David Guilkey, and Rom Mroz. 2005. "The Impact of Community-Level Variables on Individual-Level Outcomes." Sociological Methods and Research 34(1):76121.

Axinn, William, Jennifer Barber, and Dirgha Ghimire. 1997. "The Neighborhood History Calendar: A Data Collection Method Designed for Dynamic Multilevel Modeling." Sociological Methodology 27:355-92.

Axinn, William, L. Pearce, and Dirgha Ghimire. 1999. "Innovations in Life History Calendar Applications." Social Science Research 28:243-64.

Barber, Jennifer S., Ganesh P. Shivakoti, William G. Axinn, and Kishor Gajurel. 1997. "Sampling Strategies for Rural Settings: A Detailed Example from Chitwan Valley Family Study, Nepal." Nepal Population Journal 65(5):193-203.

Bebbington, Anthony. 1999. "Capitals and Capabilities: A Framework for Analyzing Peasant Viability, Rural Livelihoods and Poverty." World Development 27(12):2021-44.

Bello, Walden, Shea Cunningham, and Kheng Poh Li. 1998. A Siamese Tragedy: Development and Disintegration in Modern Thailand. London, England: Zed Books.

Biddlecom, Anne, William Axinn, and Jennifer Barber. 2005. "Environmental Effects of Family Size Preferences and Subsequent Reproductive Behavior in Nepal." Population and Environment 26(3):183-206. 
Brockerhoff, Martin. 2000. “An Urbanizing World.” Population Bulletin 55(3):1-44.

Chamratrithirong, Aphichat, Kitaya Archavanitkul, Kerry Richter, Philip Guest, Varachi Thongthai. 1995. National Migration Survey of Thailand. Nakonpathom, Thailand: Institute for Population and Social Research, Mahidol University.

Chamratrithirong, Aphichat, S. Philip Morgan, and Ronald Rindfuss. 1988. "Living Arrangements and Family Formation." Social Forces 66(4):926-50.

Curran, Sara. 2002. "Migration, Social Capital, and Environment: Considering Migrant Selectivity and Networks in Relation to Coastal Ecosystems." Population and Development Review 28:89-125.

- 2005. "Uncovering Trade, Development, and Environmental Linkages: The Case of Cassava in Thailand and Food in Europe, 1970-2002." Pp.—in Trading Morsels, Growing Hunger, Decimating Nature: Linking Food and Trade to Development and the Environment. Princeton Institute for International and Regional Studies, Princeton, NJ, February 24-26.

Dawe, David. 2005. "Increasing Water Productivity in Rice-Based Systems in Asia-Past Trends, Current Problems, and Future Prospects." Plant Production Science 8(3):22130 .

Dixon, John, Aidan Gulliver, and David Gibbon. 2001. "Introduction." Pp. 1-26 in Farming Systems and Poverty: Improving Farmers' Livelihoods in a Changing World, edited by M. Hall. Rome, Italy: UN Food and Agriculture Organization; Washington, DC: World Bank.

Ellis, Frank. 1998. "Household Strategies and Rural Diversification." Journal of Development Studies 35(1):1-38.

Entwisle, Barbara, Stephen Walsh, Ronald Rindfuss, and Aphichat Chamratrithirong. 1998. "Land-Use/Land Cover and Population Dynamics, Nang Rong, Thailand.” Pp. 449-70 in People and Pixels, edited by D. Liverman, E. Moran, R. Rindfuss, and P. Stern. Washington, DC: National Academy Press.

Entwisle, Barbara S., Stephen J. Walsh, Ronald R. Rindfuss, and Leah K. VanWeh. 2005. "Population and Upland Crop Production in Nang Rong, Thailand." Population and Environment 26(6):449-70.

Filmer, Deon and Lant H. Pritchett. 2001. "Estimating Weath Effects without Expenditure Data or Tears: An Application to Educational Enrollments in States in India." Demography 38(1):115-32.

Goldstein, Sidney. 1987. "Forms of Mobility and Their Policy Implications: Thailand and China Compared." Social Forces 65(4):915-42.

Graner, Elvira. 2001. "Labor Markets and Migration in Nepal." Mountain Research and Development 21(3):253-59.

Gray, Clark L. 2009. "Environment, Land, and Rural Out-Migration in the Southern Ecuadorian Andes." World Development 37(2):457-68.

Hathaway, Dale E. 1960. "Migration from Agriculture: The Historical Record and Its Meaning." American Economic Review 50(2):379-91.

Jokisch, Brad D. 2002. "Migration and Agricultural Change: The Case of Smallholder Agriculture in Highland Ecuador." Human Ecology 30(4):523-50.

Kandel, William and Douglas Massey. 2002. "The Culture of Migration: A Theoretical and Empirical Analysis." Social Forces 80(3):981-1004.

Kolenikov, Stanislav and Gustavo Angeles. 2004. "The Use of Discrete Data in PCA: Theory, Simulations, and Applications to Socioeconomic Indices.” MEASURE/Evaluation Project Working Paper No. WP-04-85, Carolina Population Center, Chapel Hill, NC.

Kollmair, Michael, Siddhi Manandhar, Bhim Subedi, and Susan Thieme. 2006. "New Figures and Old Stories: Migration and Remittances in Nepal." Migration Letters $3(2): 151-60$.

Leturque, Henri and Steven Wiggins. 2011. Thailand's Progress in Agriculture: Transition and Sustained Productive Growth. London, England: Overseas Development Institute.

Matthews, Stephen A., Ganesh P. Shiavkoti, and Netra Chetri. 2000. "Population Forces and Environmental Change: Observations from Western Chitwan, Nepal." Society and Natural Resources 13(8):763-75. 
Mullen, Katrina, Pauline Grosjean, and Andreas Kontoleon. 2011. "Land Tenure Arrangements and Rural-Urban Migration in China." World Development 39(1):123-33.

Muriuki, Grace W., Chris Jacobson, Clive McAlpine, Leonie Seabrook, Bronwyn Price, and Greg Baxter. 2011. "Migrating, Staying, or Moving On: Migration Dynamics in the Chyulu Hills, Kenya.” Population, Space, and Place 17:391-406.

Nepal, Ranjita and Gopal B. Thapa. 2009. "Determinants of Agricultural Commercialization and Mechanization in the Hinterland of a City in Nepal." Applied Geography 29:377-89.

Pangali, Prabhu. 1997. "From Subsistence to Commercial Production Systems: The Transformation of Asian Agriculture." American Journal of Agricultural Economics 79(2):62834.

Parnell, M. J. G. 1988. "Rural Poverty, Development, and the Environment: The Case of Northeast Thailand." Journal of Biogeography 15(1):199-208.

Rindfuss, Ronald, Barbara Entwisle, Stephen Walsh, Christine Mena, Carlos Erlien, and Clark Gray. 2007. "Frontier Land Use Change: Sythesis, Challenges, and Next Steps." Annuals of the Association of American Geographers 97(4):739-54.

Rozelle, Scott J., Edward Taylor, and Alan deBrauw. 1999. "Migration, Remittances, and Agricultural Productivity in China." American Economic Review 89(2):287-91.

Sana, Mariano and Douglas S. Massey. 2005. "Household Composition, Family Migration, and Community Context: Migrant Remittances in Four Countries.” Social Science Quarterly 86(2):510-28.

Savada, A. M., ed. 1991. Nepal: A Country Study. Washington, DC: GPO for the Library of Congress.

Seddon, David, Jagannath Adhikari, and Ganesh Gurung. 2002. "Foreign Migration and the Remittance Economy of Nepal.” Critical Asian Studies 34(1):19-20.

Shrestha, Nanda, Raja P. Velu, and Dennis Conway. 1993. "Frontier Migration and Upward Mobility: The Case of Nepal." Economic Development and Cultural Change 41 (4):787-816.

Shrestha, Shreemat. 2012. "Status of Agricultural Mechanization in Nepal." United Nations Asian and Pacific Center for Agricultural Engineering and Machinery (UNAPCAEM). Retrieved March 5, 2012 (http://www.unapcaem.org/ppta/1112RT.htm).

Stark, Oded and J. Edward Taylor. 1989. "Relative Deprivation and Internal Migration." Demography 26(1):1-14.

Taylor, J. Edward, Scott Rozelle, and Alan de Brauw. 2003. "Migration and Incomes in Source Communities: A New Economics of Migration Perspective from China." Economic Development and Cultural Change 52:75-101.

Thepent, Viboon. 2012. "Situation of Agricultural Engineering in Thailand." United Nations Asian and Pacific Center for Agricultural Engineering and Machinery (UNAPCAEM). Retrieved March 5, 2012 (http://www.unapcaem.org/ppta/1112RT.htm).

Thieme, Susan and Simone Wyss. 2005. "Migration Patterns and Remittance Transfers in Nepal: A Case Study of Sainik Basti in Western Nepal.” International Migration 43(5):60-98.

VanWey, Leah. 2003. "Land Ownership as a Determinant of Temporary Migration in Nang Rong, Thailand." European Journal of Population 19:121-45.

- 2005. "Land Ownership as a Determinant of International and Internal Migration in Mexico and Internal Migration in Thailand." International Migration Review 39(1):141-72.

Warr, Peter G. and Bhanupong Nidhiprabha. 1996. Thailand's Macroeconomic Miracle: Stable Adjustment and Sustained Growth. Washington, DC: World Bank.

White, Halbert. 1980. "A Heteroskedasticity-Consistent Covariance Matrix Estimator and a Direct Test for Heteroskedasticity.” Econometrica 48(4):817-38.

World Bank. 2008. World Development Indicators. Washington, DC: World Bank. 2012. "Nepal: Priorities for Agriculture and Rural Development." World Bank. Retrieved March 5, 2012 (http://go.worldbank.org/D9M3ORHVL0).

Zhao, Yaohui. 1999. "Leaving the Countryside: Rural-to-Urban Migration Decisions in China." American Economic Review 89(2):281-86. 